\title{
Chemotherapy for Invasive Bladder Cancer: Five Simple Rules Learned Over 30 Years
}

\author{
Derek Raghavan* \\ President, Levine Cancer Institute, Carolinas HealthCare System, Charlotte, NC, USA
}

\begin{abstract}
Invasive, clinically non-metastatic bladder cancer has a cure rate of only 50\%, when all $\mathrm{T}$ stages are considered. The pattern of relapse is dominated by systemic spread, provided that optimal surgery is practiced. Occult metastases are thus most likely to be present at first presentation. For more than 30 years, therapeutic strategies have focused on the use of systemic chemotherapy before, during or after loco-regional therapy to produce cure. More aggressive surgery and more precise radiation techniques in addition to improved chemotherapy have also been tested to improve cure rates. Genetic analysis has focused on prediction and prognostication, without yet having a major impact on outcomes. New agents have been tested in the neoadjuvant and adjuvant setting, but have not yet proven superior to standard algorithms, such as neoadjuvant MVAC chemotherapy. Many studies have tested ineffective metastatic regimens in the neoadjuvant setting without success, giving rise to the maxim that ignoring logical rules of investigation will not advance clinical practice. Leveraging molecular prognostication and immune responsiveness of urothelial cancer may produce the next era of progress. Five simple rules are proposed to guide the development of future studies.
\end{abstract}

Keywords: Invasive, bladder cancer, chemotherapy, neo-adjuvant, adjuvant, chemo-radiation, bladder preservation, gene expression, P53, gemcitabine, paclitaxel, MVAC, CMV, PD-L1, c-MET gene

Invasive bladder cancer represents a useful metaphor for the treatment strategies for all solid tumors. The past thirty years has seen the evolution of increased understanding of the molecular biology of this disease, and the application of this knowledge to the design of clinical trials. In parallel, different modalities of treatment have been added to the therapeutic armamentarium, reflecting the natural history of the disease, and the limitations of each treatment. Randomized trials have identified clear progress in improving median survival and cure rates, but the clinical application of these advances has been marred by some missteps. This review considers approaches for the future, integrating

*Correspondence to: D. Raghavan, Levine Cancer Institute, Carolinas HealthCare System, PO Box 32861, Charlotte, NC, 282322861, USA. Tel.: +1 980442 3115; Fax: +1 980442 3101; E-mail: derek.raghavan@carolinashealthcare.org. knowledge gained from the past three decades, and proposes rules (Table 1) for the rational development of future treatment strategies.

\section{RULE 1: UNDERSTAND THE COMPLEX BIOLOGY OF INVASIVE BLADDER CANCER WHEN DESIGNING TRIALS}

Invasive, clinically non-metastatic bladder cancer, representing about $20 \%$ of new cases, includes tumors that penetrate through lamina propria into muscle and beyond. Thus more than 17,000 new cases occur each year in the USA, and also some cases of non-invasive bladder cancer eventually become invasive, but are not reflected in national incidence figures for invasive disease. In the USA, a reasonable estimate is that more than 20,000 patients require treatment for 
Table 1

Design rules for neoadjuvant bladder cancer trials

\begin{tabular}{|c|c|c|}
\hline & Specifics & Impact of failure to observe rules \\
\hline Rule 1 & Incorporate complex biology & Failure of single agent chemotherapy in randomized neoadjuvant trials \\
\hline Rule 2 & Avoid variable constants & $\begin{array}{l}\text { Impact of suboptimal surgery: } \\
\text { worse survival curves for control groups } \\
\text { possible impact in adjuvant trials - e.g. } \mathrm{N}_{\mathrm{o}} \text { disease }\end{array}$ \\
\hline Rule 3 & Repetition doesn't make it right & $\begin{array}{l}\text { Serial reports and overviews of RTOG studies: } \\
\text { dilutes impact of long-term follow-up in survival curves } \\
\text { large numbers still do not prove superiority }\end{array}$ \\
\hline Rule 4 & Randomization trumps historical controls & $\begin{array}{l}\text { Phase II single agent neoadjuvant trials suggested possible survival } \\
\text { benefit** }\end{array}$ \\
\hline Rule 5 & If it doesn't make sense, it's probably wrong & $\begin{array}{l}\text { Use of disease-free interval as primary parameter for adjuvant trials } \\
\text { Misinterpretation of meta-analyses of adjuvant therapy - inclusion of } \\
\text { inappropriate sets of data } \\
\text { Failure to implement level } 1 \text { clinical trials data in treatment of invasive } \\
\text { disease }\end{array}$ \\
\hline
\end{tabular}

** By comparison, phase III trials proved clinical and statistical benefit of neoadjuvant MULTI-AGENT chemotherapy.

invasive bladder cancer per year [1]. Most bladder cancers $(90 \%)$ are urothelial carcinomas (UC), formerly termed "transitional cell carcinomas" (TCC) [1, 2], which is the focus of this review. Other cell types include squamous cell carcinoma, adenocarcinoma, small cell carcinoma and very rarely sarcoma, lymphoma, or melanoma [3, 4]. Invasive bladder tumors are usually moderately to poorly differentiated $[1,2]$. Our xenograft studies suggested the existence of a stem cell tumor of origin in bladder cancer, explaining why urothelial carcinoma may coexist with (and perhaps give rise to squamous and glandular patterns of cancer [5]. We have also demonstrated in these models clonal heterogeneity, reflected in histology and ultrastructure, tumor growth kinetics, expression of growth factors and their receptors, and response to treatment $[5,6]$.

When planning treatment of invasive disease, it is important to consider conventional predictors of outcome - stage and grade are the dominant prognosticators [1, 2], and solid growth pattern, large size, aneuploidy, lympho-vascular invasion and the presence of hydronephrosis may also have an adverse prognostic import, as reviewed previously $[1,2]$.

\section{Molecular biology}

The genomic revolution has evolved, in part, in parallel with our understanding of the molecular biology of bladder cancer [7-14]. An early study reported that lack of expression of ABO blood group substances on the surface of noninvasive bladder cancer cells correlated with higher rates of relapse and progression to invasion [7], and it was speculated that this could either reflect the impact of differentiation or potentially immune reactivity.
Invasive and less differentiated tumors of the bladder are associated with aberrations of chromosome 17, often with P53 mutations, and it appears that P53, Rb and $\mathrm{P} 21$ are linked, functioning as a complex, with outcome being linked to the expression or absence of each component of the complex [8-10]. This remains controversial and more recent studies have not confirmed these associations $[11,12]$. Of particular importance was a recent randomized trial that tested the hypotheses that P53 mutation connotes for worse natural history, and that improved adjuvant response would be associated with P53 mutation [12]. Neither hypothesis was validated, although it is important to note that poor accrual and patient refusal to participate in this randomization, and an unexpectedly low recurrence rate, may have contributed to the unexpected result.

Other studies initially suggested that P53 mutation was associated with resistance to neoadjuvant chemotherapy with the methotrexate-vinblastinedoxorubicin(Adriamycin ${ }^{\mathrm{R}}$ )-cisplatin (MVAC) regimen [15]. A detailed study of molecular prognosticators in patients treated with the MVAC or cisplatin-methotrexate-vinblastine (CMV) regimens for advanced bladder cancer at Princess Margaret Hospital, Toronto, did not identify any prognostic impact from expression of P53 immunohistochemically [11]. It was not clear whether this reflected a true lack of prognostic relevance or is an artifact of methodology or small sample size. That said, in this small study, metallothionein expression did have statistically significant prognostic implications.

Metallothioneins are a family of sulfhydrylcontaining cysteine rich compounds that are involved in absorption, transport and metabolism of heavy metals, and which may be related to resistance to cisplatin and alkylating agents [16]. Increased concentration of 
metallothionein in mice caused a reduction of nephrotoxicity, accompanied by cisplatin resistance in mouse bladder cancer [17], an observation supported by clinical studies [11].

Another sulfhydryl rich compound, the intracellular scavenger, glutathione, decreases the available level of cytotoxic agents, such as cisplatin, within tumor cells, thus also correlating with resistance. In bladder cancer xenografts, we identified high levels of glutathione [18], higher than are found in melanoma and ovarian cancer, the classical models of the role of glutathione in cytotoxic resistance. We also showed this protein in present in human bladder tumor biopsy specimens in higher concentrations than those found in normal bladder tissue. The measurement of this protein has not become a standard predictive test in the management of bladder cancer, although there are several sets of preliminary data that implicate glutathione and glutathione-S-transferase in the biology of responses to chemotherapy.

RAS mutations are associated with loss of differentiation and a worse prognosis [13], and genetic markers of tumor vascularity and angiogenesis also reflect worse natural history and response to treatment [14]. Some of these genes may interact, at a molecular level, with functions of the P53 tumor suppressor gene.

The epidermal growth factor receptor (EGFR) is another prognostic determinant for bladder cancer [19]. This cell surface protein, with known cell growth regulatory functions, is correlated with expression of P53, aneuploidy, and invasive growth [19], but may also play a role in resistance to cytotoxic agents, such as cisplatin [20]. The Radiation Therapy Oncology Group (RTOG) have carried out retrospective analyses of their series of cases treated with radiotherapy and cisplatin-based chemotherapy, and have demonstrated that expression of EGFR is associated with improved outcome, including response to chemoradiation, whereas expression of the her-2-neu gene correlates in univariate analysis with reduced response and survival after such treatment [21]. The transferrin receptor [22], also located on the surface of bladder cancer cells, which has metallic ion transport functions, also correlates with natural or treated history of invasive bladder cancer.

The multi-drug resistance (MDR) phenotype or p-glycoprotein expression has also been shown to affect response of bladder cancer to certain cytotoxics, such as doxorubicin and the vinca alkaloids [23], and this may have confounded some of the above studies related to the impact of P53 on response to these agents.
Oligonucleotide arrays also have been used to analyze the transcript profiles of bladder tumors and immunohistochemical analyses of tissue arrays have validated the associations between marker expression, staging and outcome. It has been claimed that they are able to prognosticate with more than $80 \%$ accuracy [24]. At a more sophisticated level, transcript profiles of more than 100 bladder specimens, representing the spectrum from normal to relatively benign to malignant disease, have been studied in an attempt to identify useful novel prognosticators [25]. In an interesting molecular fishing expedition that using available technology, but was not necessarily hypothesis-driven, a hierarchy of determinants was reported, each associated with a difference in survival, including peptidyl propyl isomerase A, nuclear RNA export factor 1, tetratricopeptide repeat domain $\mathrm{G}$, hematopoietic cell specific Lyn substrate 1, ankyrin G, baculoviral IAP repeat-containing 3 , intercellular adhesion molecule 1 and TP53-activated protein 1. Several of these did not relate to a strong underlying biological hypothesis and have not been pursued clinically.

Thus overlapping and interacting molecular functions regulate growth, differentiation, response to treatment and prognosis of bladder cancer. However, it is important to identify real, biologically relevant factors and distinguish them from innocent bystanders revealed by batteries of complex molecular tests. Several of these oncogenes and suppressor genes may be suitable candidates for gene or targeted therapy, or for downstream regulation through inhibitors of transcription and translation. Others have extended these concepts by attempting to develop a molecular taxonomy for bladder cancer, and have identified a genomically unstable variant, which shares most of the features of invasive bladder cancer, with a complex molecular construction that suggests potential responsiveness to immune manipulation and the need for multi-agent cytotoxic management $[26,27]$. This prediction has certainly been validated by the failures of simple, single cytotoxic agent studies of the past [28].

Another emerging domain for potential management of invasive bladder cancer is our expanding understanding of the molecular biology of the immune response. The possibility that expression of blood group antigens on the surface of bladder cancer cells impacts survival [7] via immunological mechanisms, and the evidence that stimulation of the immune response via intravesical BCG is associated with regression of non-invasive bladder cancer [29] suggest another avenue for treatment of invasive disease. However, a small, underpowered Brazilian study 
suggested that this approach is not effective for invasive disease [30].

However, at the Annual Scientific Meeting of the American Society of Clinical Oncology in 2014, cabozantanib, a tyrosine kinase inhibitor which is active against MET and VEGFR, was shown to inhibit immunosuppressive $\mathrm{T}$ cell subsets with an apparent anti-cancer effect in metastatic bladder cancer [31]. Of importance, this agent has already been shown to have clinically meaningful activity against cancers of prostate and kidney. While this was only a preliminary communication that requires further validation, it suggests a potential avenue of novel therapy for invasive bladder cancer.

In parallel, others have shown that PDL-1, a gene involved in the biology of $\mathrm{T}$ cell inhibition and response, is heavily expressed in bladder cancer, and that MPDL3280A, an agent that reacts with PDL-1, inhibiting the interaction between PDL-1 and PD1, causes objective tumor responses [32]. The level of anticancer effect appears to correlate with expression of PDL-1, and there is also a correlation with survival. In view of the modest toxicity profile and apparent anticancer efficacy in bladder cancer, it seems likely that MPDL3280A and similar agents will find a useful role in the management of metastatic bladder cancer, and potentially as an ancillary in neoadjuvant or classical adjuvant therapy.

Thus it seems that the integration of our evolved concepts of molecular prognostication and prediction, augmented by our newly defined interest in immune-response in invasive bladder cancer, and the recognition of the need to address multiple targets in our therapy strategy affords the most likely laboratorybased approach to rational trial design and progress for the future. In constructing any molecular taxonomy, we need to include genes that are logically relevant to the biology of response, as summarized above, in addition to those that are randomly available in the commercially available or other panels.

\section{RULE 2: VARIABLE CONSTANTS CAN IMPAIR OUTCOMES - E.G. UNDERSTAND THE CRITICAL ROLE OF OPTIMAL SURGERY WHEN DESIGNING TRIALS}

The least aggressive surgical treatment of bladder cancer is transurethral resection (TUR) or fulguration, which removes the tumor endoscopically, while attempting to spare the bladder. Several early series, and the programs of chemo-radiation have relied upon this approach $[33,34]$. While there is the clear benefit of bladder retention, there is less certainty from this approach regarding staging and true tumor clearance, particularly as the limitations of non-invasive imaging are well known.

Partial cystectomy, with removal of the tumorcontaining portion of the bladder in highly selected cases, gives greater certainty of local tumor clearance, usually with retention of the bladder in situ [35]. In most instances, the pathological staging with regard to lymph nodes is less robust when partial cystectomy is performed.

Thus both of these conservative options provide less certainty with respect to true clearance of loco-regional disease, which may impact the cure rate, even when combined with systemic therapy (and thus may impact the apparent effect of systemic therapy).

The standard of care for most patients with invasive bladder cancer is radical cystectomy, which includes clearance of draining pelvic lymph nodes [36-38]. The cure rate depends on well-defined prognostic factors, including conventional indices, such as stage and grade, and the more recent prognostic factors discussed above. In addition, it appears that delay in cystectomy may lead to impaired survival [38]. Cure is even possible from surgery alone in locally advanced disease [36], although the chance is much lower. It has become clear that surgical experience is an important factor in the success of local tumor clearance [39], and thus may have a substantial impact on the results of combined modality treatment.

In the past decade, laparoscopic surgery has been introduced into the care of invasive bladder cancer. The initial reports were encouraging, although it was clear that there is a substantial learning curve for the tyro, during which local complications are higher and the benefits less obvious [40, 41]. Despite a great deal of rhetoric, this technology has rarely been tested in a randomized fashion, and the sole, published early report of a randomized trial has seriously questioned the true benefits of this surgical technology [42]. One should always be cautious in the interpretations of non-randomized studies comparing laparoscopic and conventional surgical approaches because of the risk of substantial case selection bias [41].

I have a real concern that the rush to introduce unvalidated, novel surgical techniques, without the benefit of true comparison against standard surgical procedures, may yield worse outcomes that will be masked by chemotherapy. For example, as discussed below, the purported usefulness of adjuvant chemotherapy in the EORTC randomized trial testing its utility [43] may 
well reflect a compensatory effect that offsets inadequate surgery.

\section{RULE 3: SAYING THE SAME THING REPEATEDLY IS NOT THE BEST WAY TO PROVE A CONCEPT}

\section{Chemoradiation and bladder preservation techniques}

The use of radiotherapy as an alternative to cystectomy for invasive bladder cancer was previously favored in parts of Europe and Canada, although the pendulum has swung towards radical cystectomy in recent years because of the perception of higher surgical cure rates. Of importance, literature comparisons between the results of surgery and radiotherapy for bladder cancer, reflect the comparison of surgical versus clinical staging, and patients treated in radiation series are characteristically older and less robust. The traditional approaches to radiotherapy included doses of external beam irradiation in the range of 50-70 Gy, with a higher level of local control achieved in series reporting higher dose targets above 65-70 Gy [44, 45]. Ideal radiotherapy candidates have had aggressive pre-radiotherapy TUR, absence of extralesional carcinoma-in-situ, no anemia, and no hydronephrosis [46].

Of particular importance is the definition of the site and size of the tumor, and treatment planning should require a planning $\mathrm{CT}$ scan in the prone position, with periodic on-treatment $\mathrm{CT}$ scan assessment to ensure adequacy of ongoing coverage of the tumor and tumor bed within the treatment fields. Analogous to the quality of surgery, radiation technique and dose have a substantial impact on the outcome of chemo-radiation approaches.

Investigators at Massachusetts General Hospital [47], from Europe [48] and within the Radiation Treatment Oncology Group (RTOG) [49] have made seminal contributions in evolving the technology of chemo-radiation for bladder cancer, and providing an option as an alternative to cystectomy. Unfortunately, although it has been demonstrated quite clearly that chemo-radiation produces better local tumor control than radiation alone [50], none of their studies have addressed a randomized comparison against combined modality approaches with surgery as the definitive treatment. The pattern of serial reporting and updates, with historical comparisons [49], while impressive, really has not helped us to shape a definitive approach to treatment of all patients. Unfortunately this approach has loaded long-term follow-up reports with significant numbers of less mature cases, thus with the potential to artificially inflate the survival curves. In fairness, one should note that it is highly unlikely that the broad community of urological oncologists would have supported a randomized trial of surgery versus any type of chemoradiation or radiotherapy for invasive bladder cancer.

James et al. [51] have recently reported the results of a randomized comparison of chemoradiation with 5-fluorouracil-mitomycin $\mathrm{C}$ versus radiation alone. In a series dominated by patients with clinical stage $\mathrm{T} 2$ disease, this trial demonstrated improved response rate, progression-free and overall survival achieved by chemoradiation [51].

\section{RULE 4: RANDOMIZED TRIALS PROVE MORE THAN HISTORICAL COMPARISONS - DEVELOPMENT OF NEOADJUVANT CHEMOTHERAPY}

More than 30 years ago, we began to develop combined modality approaches, incorporating systemic chemotherapy with definitive local treatments, based on the following concepts [28, 52-54]:

- systemic chemotherapy may reduce the extent of local tumor;

- it allows clinical assessment of chemoresponsiveness of the tumor, thus allowing more rational decisions to be made regarding continuation of chemotherapy;

- it may control occult micro-metastases;

- if radiotherapy is planned, it may cause enhanced radiation responsiveness via synergistic effects between some cytotoxics (e.g. doxorubicin, cisplatin, 5-fluorouracil, mitomycin, gemcitabine) and the biological impact of radiation.

In the early 1980s, Mark Soloway and I reported phase II trials testing the utility of single agent cisplatin, in association with radiotherapy or surgery, to improve outcomes for invasive bladder cancer, based on the postulates above [52-54]. Although our initial studies were very promising, with high objective response rates, and possible improvements in survival, I was concerned that these could represent artefacts of phase II design and initiated a randomized trial to test the hypothesis. This and other randomized trials did not confirm the initial observations [55]. When one considers the molecular complexity of bladder cancer, this is not surprising, but this knowledge was not available 
Table 2

Key randomized trials of chemotherapy for invasive bladder cancer

\begin{tabular}{|c|c|c|c|c|c|}
\hline Series & Regimen & $\begin{array}{l}\text { Definitive local } \\
\text { therapy }\end{array}$ & $\begin{array}{c}\text { Median survival } \\
\pm \text { chemotherapy (months) }\end{array}$ & $\begin{array}{c}\text { Actuarial long term } \\
\text { survival } \pm \text { chemotherapy }\end{array}$ & $\begin{array}{c}P \text { value of } \\
\text { difference in survival }\end{array}$ \\
\hline \multicolumn{6}{|l|}{ NEOADJUVANT } \\
\hline MRC-EORTC & CMV & RT or cystectomy & $44 / 37.5$ & $35 \% / 30 \%$ at $10 \mathrm{YR}$ & 0.037 \\
\hline US Intergroup & MVDC & Cystectomy & $77 / 46$ & $42 \% / 35 \%$ at $10 \mathrm{YR}$ & 0.06 \\
\hline Nordic-1 & $\mathrm{DC}$ & Cystectomy & $\mathrm{NR} / 72$ & $59 \% / 51 \%$ at $5 \mathrm{YR}$ & 0.03 (T3-4a only) \\
\hline RTOG & CMV & Chemo-radiation & $36 / 36$ & $48 \% / 49 \%$ at $5 \mathrm{YR}$ & NS \\
\hline \multicolumn{6}{|l|}{ AJUVANT } \\
\hline EORTC & MVDC or GC & Cystectomy & $81 / 55$ & $44 \% / 39 \%$ at 5 YR & 0.13 \\
\hline Stanford & CMV & Cystectomy & $63 / 36$ & $42 \% / 38 \%$ at $5 \mathrm{YR}$ & 0.32 \\
\hline USC & CDCy & Cystectomy & $52 / 30$ & $44 \% / 39 \%$ at $5 \mathrm{YR}$ & $0.0062 *$ \\
\hline Italian (Cognetti) & GC & Cystectomy & $38 / 58$ & $44 \% / 44 \%$ at $6.5 \mathrm{YR}$ & 0.7 (favors no chemotherapy) \\
\hline
\end{tabular}

Abbreviations: C, cisplatin; D, doxorubicin; M, methotrexate; Cy, Cyclophosphamide; V, vinblastine; G: gemcitabine; MRC-EORTC, Medical Research Council/European Organization for Research and Treatment of Cancer; RT, radiotherapy; NR not reached. NS non-significant. * Note irregularities of accrual, failure to obey randomization rules, only 91 cases.

at the time that we designed these studies. It is likely that the apparent improvement in outcome with single agent neoadjuvant therapy actually reflected the introduction of CT scanning into routine clinical practice at that time - thus creating stage migration, and moving patients with heretofore occult abdominal and pelvic nodal involvement into the category of inoperable disease [28]

In the mid-1980s, the MVAC and CMV regimens were shown to be highly active against metastatic bladder cancer with apparently superior results to single agent therapy [56, 57], an improvement confirmed in an international randomized trial [58]. With emerging understanding of the molecular complexity of bladder cancer, it was logical to test these complex regimens in the neoadjuvant setting and initial results were again very encouraging $[59,60]$.

Randomized clinical trials were then designed to test the use of neoadjuvant MVAC and CMV in association with cystectomy or radiotherapy, and I was privileged to be involved in the design and/or execution of two key trials. The MRC-EORTC-International trial of neoadjuvant $\mathrm{CMV}$, which recruited 976 cases between 1989-1995, was designed to identify a $10 \%$ difference in long-term survival, but failed to do so (achieving a 6-7\% difference in outcome) and was thus reported initially as a "negative" trial [61]; however, a recent long-term update showed a sustained 6\% 10 year survival benefit from neoadjuvant CMV, with a more obvious impact in surgical cases [62]. The hazard ratio of. 84 (indicating a $16 \%$ reduction in death) favored combined therapy $(p=0.037)$. By contrast, the RTOG, also testing the utility of neo-adjuvant CMV chemotherapy followed by chemo-radiation versus chemo-radiation alone, showed identical three year survival [63]. This may have reflected a different patient population or perhaps the impact of the cisplatin chemotherapy in the chemo-radiation components of each treatment arm.

Although the North American Intergroup trial of neo-adjuvant MVAC revealed a very dramatic difference in median survival (6 years versus 3.8 years), the absolute improvement in long-term survival and potential increment of cure rate was also of the order of 7 percent [64]. This improvement is consistent with the Nordic cooperative group trial 1 [65] and most cisplatin-based combination regimens, as summarized in our meta-analysis [66] (see also Table 2).

These data suggest that deeply invasive bladder cancer should be treated by neoadjuvant MVAC or CMV chemotherapy followed by cystectomy if the patients are deemed fit for chemotherapy and surgery. For less physically robust patients, the combination of gemcitabine-cisplatin is a reasonable alternative, although there are no level 1 data to prove its equivalence to the regimens listed above.

\section{RULE 5: IF IT DOESN'T MAKE SENSE, IT'S PROBABLY WRONG - ADJUVANT CHEMOTHERAPY FOR INVASIVE BLADDER CANCER}

\section{Adjuvant chemotherapy}

Adjuvant (postoperative) chemotherapy has shown some promise in improving disease-free survival for patients with invasive bladder cancer. Randomized trials assessing the utility of combination chemotherapy (such as the combination of methotrexate, vinblastine, and cisplatin, with or without doxorubicin or epiribicin - the CMV, MVAC or MVEC regimens), administered after radical cystectomy for patients with deeply invasive disease and/or involved lymph nodes, have all shown improved disease-free survival [66-69]. 
However, many of the published trials have been weakened by poor statistical design or execution, and these studies have not demonstrated a statistically significant improvement in overall survival. For example, in one study from Germany, there was an uneven distribution of salvage chemotherapy (with one arm not providing for routine chemotherapy at any time after relapse, but rather referral to palliative care), making the trial a test of chemotherapy at any time after cystectomy, rather than addressing the role of early chemotherapy as classical adjuvant treatment [69]. The interpretation of data in this study was confounded in one report by the addition of non-randomized cases into the follow-up analysis [70]. This study was included in a meta-analysis that purported to demonstrate a benefit for adjuvant chemotherapy, despite the fact that it didn't actually test that hypothesis [71].

The study reported from Stanford University [67] was predicated on disease-free survival, and thus was correctly closed early by its Data Safety and Monitoring Committee, and there were insufficient cases to provide a meaningful overall survival analysis. As noted above, disease-free survival benefit should not be the key parameter for success of adjuvant studies as it negates the impact of salvage therapy [72].

The EORTC attempted to address this issue in a welldesigned, randomized trial, in which standard local therapy has been compared to standard local therapy plus the addition of adjuvant chemotherapy [43]. Unfortunately this important trial closed prematurely due to lack of accrual, presumably because of preconceptions of participating clinicians (or their patients) about the use of chemotherapy, and it will now be challenging to produce level 1 data to resolve the issue. In a recent report, these investigators noted a statistically significant disease-free survival benefit, but only a nonsignificant trend in favor of chemotherapy. Their most paradoxical observation was that the only group with a meaningful impact was that with node NEGATIVE, locally advanced disease, suggesting that chemotherapy may have overcome inadequate surgery. Logic might have dictated that the likely group to show benefit would have been those with nodal involvement.

Also relevant to this issue is the randomized P53 study noted above [12]. While this study was not designed to address the utility of adjuvant chemotherapy per se, it is noteworthy that the patients who received 3 cycles of adjuvant MVAC did not appear to have improved overall survival, compared with those who were treated with surgery alone. This may have been due to the P53-mutant status of the cancers, but the data clearly did not provide any support for the rou- tine use of adjuvant chemotherapy for invasive bladder cancer. Furthermore, an Italian randomized trial, assessing the utility of adjuvant gemcitabine-cisplatin (which seems to have found its way into "routine" use as an alternative to MVAC or CMV without level 1 supporting data), actually showed a non-significant survival trend AGAINST adjuvant chemotherapy [73].

\section{Current patterns of practice}

Another practice that doesn't make sense to me is as follows: Despite the extensive evidence of improved survival from neoadjuvant combination chemotherapy and cystectomy or radiotherapy for invasive bladder cancer, compared to local modalities alone, surveys of patterns of practice consistently indicate that most patients do not receive this treatment. A recent study of the SEER-Medicare data base for 1992-2002 (which antedated the publications of the randomized trials) indicated that such treatment is rarely used [74]. A report from the National Cancer Data Base showed similar data for the period 1998-2003 [75]. However, two studies from contemporary time frames show that far fewer than $50 \%$ of patients receive such treatment $[76,77]$, despite the well-publicized, definitive survival benefit. Sadly it appears that the gate-keepers of invasive bladder cancer continue to believe that adjuvant chemotherapy yields survival benefit, and thus offer radical cystectomy with ad hoc use of subsequent chemotherapy (or no chemotherapy), depending on the pathology of the resected specimens. Perhaps the negative outcome of the EORTC trial will cause a change in this approach.

\section{THE FUTURE}

Given the extensive data on the use of localized therapies for invasive bladder cancer, such as cystectomy and/or radiotherapy, it seems unlikely that a quantum leap of technology will allow innovations in these modalities to have a major impact on cure rates. As noted above, there are extensive level 2 data suggesting that laparoscopic and robotic approaches to surgery may reduce morbidity, although this view is controversial [42]. To date, there are no level 1-2 data to suggest that proton beam radiotherapy will improve cure rates, but the NRG Cancer Trials Group is currently assessing the utility of adjuvant radiotherapy to reduce pelvic recurrence in its randomized GU-001 trial for pT3-4 disease.

The anticancer efficacy of gemcitabine, the taxanes, some of the novel platinum complexes and tyrosine 
kinase inhibitors against recurrent and metastatic bladder cancer have been previously documented. Analogous to past clinical modeling, these constructs have been applied to the treatment of invasive bladder cancer.

Perhaps of greatest interest has been the potential for using gemcitabine-cisplatin as neoadjuvant or adjuvant chemotherapy, based on its similar activity (with less toxicity) to MVAC chemotherapy for metastatic disease [78]. No definitive trial has proven that gemcitabine-cisplatin provides a survival benefit in addition to definitive treatment in either the neoadjuvant or adjuvant setting. The problems of historical, non-randomized or under-powered comparisons, with the risk of case selection bias or follow-up bias, preclude meaningful assessment of the published data. My approach, when patients are not sufficiently robust to tolerate the MVAC or CMV regimens, is to discuss the potential utility of gemcitabine-cisplatin, explaining that this is likely to be less toxic, based on comparisons in patients with metastatic disease, but that it has not been validated in the neoadjuvant or adjuvant setting. Of course, the majority of patients who cannot tolerate MVAC or CMV will be unlikely to withstand the physical impact of radical cystectomy, so the discussion if often moot. However, another option, for the patient with renal dysfunction and no other medical issues, has been consideration of more gentle chemotherapy, such as the combination of gemcitabine-carboplatin. When approaching such a case, I first exclude renal tract obstruction by the tumor as the cause of the renal failure; if this is the situation, I usually resort to ureteral stenting or a nephrostomy and review renal function with a view to the use of standard chemotherapy. Where there is no ability to improve on a creatinine clearance of about $40 \mathrm{ml} / \mathrm{min}$, it is reasonable to substitute carboplatin, although level 1 data to support this approach as beneficial over cystectomy alone have not been published.

Another regimen that was recently reported in a randomized comparison against MVAC for metastatic disease is the combination of gemcitabine, cisplatin and paclitaxel (GCP) [79]. Although there was a small increase in response rate from GCP, there was no significant survival benefit. Nonetheless, a Spanish cooperative group recently reported a survival benefit from adjuvant GCP after cystectomy in a presentation at the Annual Scientific Meeting of the American Society of Clinical Oncology [80], but their data were preliminary and there has been no definite follow up after an additional three years.
There have been recent reports at scientific meetings of the use agents targeting the epidermal growth factor receptor in the neoadjuvant setting for invasive bladder cancer [81], but the publication was not definitive with regard to extent or duration of response, or survival outcomes, and the data have not been peer-reviewed. Many studies have addressed the use of novel therapies in the neoadjuvant setting, and this approach has been quite useful as a modeling technique, but there are no level 1 data to prove clinical utility of these novel agents at this time.

It seems likely that molecular prognostication and prediction will influence our approach to invasive bladder cancer in the future [25-27, 32] as we have made scant progress in surgery, radiotherapy or chemotherapy in the past decade. The Southwest Oncology Group is currently testing the utility of molecular prognostication in the so-called CoXEN study, SWOG 1314, which tests an established molecular panel [82, 83] for its predictive utility in the management of invasive bladder cancer. Of great interest has been a recent publication from the University of Southern California, describing an elegant statistical approach to comparison of conventional clinical prognosticators versus a novel genomic classification system [84]. This cautious report indicated that the undefined panel of gene expression traits clustered to provide more accurate prognostication than do standard clinical nomograms. Also of interest, given the previous study from USC [68] supporting the survival benefit from adjuvant chemotherapy, this report suggested that, in multivariable analysis, adjuvant chemotherapy does not confer prognostic benefit; however, it is important to emphasize that this was a post hoc analysis and did not represent level 1 data [84].

Of more immediate potential benefit, the recent studies in the application of PDL-1 inhibition to the management of bladder cancer [32], with established activity against metastatic disease and potential utility to be tested in the neoadjuvant or adjuvant setting, present exciting opportunities. In parallel, the level of expression of PDL-1 in bladder cancer appears to offer a useful prognostic tool, correlating with the interplay between the biology of bladder cancer and resistance to its growth from the immune system.

As part of improving outcomes in the management of invasive bladder cancer, it also will be important to continue to educate patients and their physicians about the progress that has been made, and to ensure that the medical community capitalizes fully on those gains. 


\section{SUMMARY}

Systemic chemotherapy has been shown in statistically significant and clinically relevant randomized trials to improve outcomes of definitive local treatment when used as first-line (neo-adjuvant) treatment. Classical adjuvant therapy has been shown to prolong disease free survival, and appears to produce an improved non-significant trend in overall survival, but no clinical trials have been completed to prove a significant survival benefit from this approach. Novel biochemical, immunological and molecular predictors of prognosis and response to treatment are being evaluated as aids to clinical management, although definitive proof of their clinical usefulness is not available. The substantial changes in diagnosis and management will ultimately improve survival from invasive bladder cancer, while reducing the toxicity of treatment. Welldesigned clinical trials, linked to sophisticated and thoughtfully designed molecular studies, will be our pathway to the future.

\section{REFERENCES}

[1] Raghavan D, Shipley WU, Garnick MB, et al. Biology and management of bladder cancer. N Engl J Med 1990;322:112933.

[2] Cote RJ, Mitra AP, Amin MB. Bladder and Urethra. In: Weidner N, Cote RJ, Suster S, Weiss LM (editors). Modern Surgical Pathology, 2nd edition. Philadelphia, PA; Saunders; 2009, Chapter 31, pp. 1079ff.

[3] Siefker-Radtke AO, Czerniak BA, Dinney CP, Millikan RE. Uncommon cancers of the bladder. In: Raghavan D, Blanke $\mathrm{CD}$, Johnson DH et al, eds. Textbook of Uncommon Cancer. 4th edition. Hoboken: Wiley-Blackwell; 2012:23-33.

[4] Swanson and Sternberg Sternberg, C.N. and Swanson, D.A. Non-transitional cell bladder cancer. In Raghavan D, Scher HI, Leibel S, Lange PH. (eds.), Principles and Practice of Genitourinary Oncology, Philadelphia, Lippincott-Raven, 1997, pp. 315-330.

[5] Brown JL, Russell PJ, Philips J, Wotherspoon J, Raghavan D. Clonal analysis of a bladder cancer cell line: An experimental model of tumour heterogeneity. Br J Cancer 1990;61:369-76.

[6] Russell PJ, Raghavan D, Gregory P, et al. Bladder cancer xenografts: A model of tumor cell heterogeneity. Cancer Res 1986;46:2035-40.

[7] Limas C, Lange PH, Fraley EE, Vessella RL. ABH antigens in transitional cell tumors of the urinary bladder: Correlation with the clinical course. Cancer 1979;44:2099-107.

[8] Esrig D, Elmajian D, Groshen S, et al. Accumulation of nuclear p53 and tumor progression in bladder cancer. New Engl J Med 1994;331:1259-64.

[9] Cote RJ, Dunn MD, Chatterjee SJ, et al. Elevated and absent $\mathrm{pRb}$ expression is associated with bladder cancer progression and has cooperative effects with p53. Cancer Res 1998;58:1090-4.

[10] Stein JP, Ginsberg DA, Grossfeld GD, et al. Effect of $\mathrm{p} 21^{\mathrm{WAF} 1 / \mathrm{CIP} 1}$ expression on tumor progression in bladder cancer. J Natl Cancer Inst 1998;90:1072-9.
[11] Siu LL, Banerjee D, Khurana RJ, et al. The prognostic role of p53, metallothionein, P-glycoprotein, and MIB-1 in muscle invasive urothelial transitional cell carcinoma. Clin Cancer Res 1998;4:559-65.

[12] Stadler WM, Lerner SP, Groshen S, et al. Phase III study of molecularly targeted adjuvant therapy in locally advanced urothelial cancer of the bladder, based on P53 status. J Clin Oncol 2011;29:3443-9.

[13] Theodorescu D, Cornil I, Fernandez BJ, Kerbel RS. Overexpression of normal and mutated forms of HRAS induces orthotopic bladder invasion in a human transitional cell carcinoma. Proc Natl Acad Sci U S A 1990;7:9047-51.

[14] Grossfeld GD, Ginsberg DA, Stein JP, et al. Thrombospondin1 expression in bladder cancer: Association with p53 alterations, tumor angiogenesis, and tumor progression. J Natl Cancer Inst 1997;89:219-27.

[15] Sarkis A, Bajorin D, Reuter V, et al. Prognostic value of p53 nuclear overexpression in patients with invasive bladder cancer treated with neoadjuvant MVAC. J Clin Oncol 1995;13:1384-90.

[16] Kelley SL, Basu A, Teicher BA, et al. Overexpression of metallothionein confers resistance to anticancer drugs. Science 1988;241:1813-5.

[17] Satoh M, Kloth DM, Kadhim SA, et al. Modulation of both cisplatin nephrotoxicity and drug resistance in murine bladder tumor by controlling metallothionein synthesis. Cancer Res 1993;53:1829-32.

[18] Pendyala L, Velagapudi S, Toth K, Glaves D, Creaven PJ, Raghavan D. Translational studies of glutathione in bladder cancer cell lines and human specimens. Clin Cancer Res 1997;3:793-8.

[19] Neal DE, Marsh C, Bennett MK, et al. Epidermal-growthfactor receptors in human bladder cancer: Comparison of invasive and superficial tumours. Lancet 1985;1:366-8.

[20] Lipponen P, Eskelinen M. Expression of epidermal growth factor receptor in bladder cancer as related to established prognostic factors, oncoprotein (c-erbB-2, p53) expression and long-term prognosis. Brit J Cancer 1994;69:1120-5.

[21] Chakravarti A, Winter K, Wu CL, et al. Expression of the epidermal growth factor receptor and Her-2 are predictors of favorable outcome and reduced complete response rates, respectively, in patients with muscle-invading bladder cancers treated by concurrent radiation and cisplatin-based chemotherapy: A report from the Radiation Therapy Oncology Group. Int J Radiation Oncol Biol Phys 2005;62:309-17.

[22] Seymour GJ, Walsh MD, Levin MR, Strutton G, Gardiner RA. Transferrin receptor expression by human bladder transitional cell carcinoma. Urol Res 1987;15:341-4.

[23] Petrylak DP, Scher HI, Reuter V, O'Brien JP, CordonCardo C. P-glycoprotein expression in primary and metastatic transitional cell carcinoma of the bladder. Ann Oncol 1994;3:835-40.

[24] Sanchez-Carbayo M, Socci ND, Lozano J, Saint F, CordonCardo C. Defining molecular profiles of poor outcome in patients with invasive bladder cancer using oligonucleotide microarrays. J Clin Oncol 2006;24:778-89.

[25] Takata R, Katagiri T, Kanehira M, et al. Predicting response to methotrexate, vinblastine, doxorubicin, and cisplatin neoadjuvant chemotherapy for bladder cancers through genome-wide gene expression profiling. Clin Cancer Res 2005;11:2625-36.

[26] Sjodahl G, Lauss M, Lovgren K, et al. A molecular taxonomy for urothelial carcinoma. Clin Cancer Res 2012;18:3377-86.

[27] Sjodahl G, Lovgren K, Lauss M, et al. Toward a molecular pathologic classification of urothelial carcinoma. Am J Pathology 2013;183:681-91. 
[28] Raghavan D. Pre-emptive (neo-adjuvant) intravenous chemotherapy for invasive bladder cancer. Brit J Urol 1988;61:1-8

[29] Morales A, Eidinger D, Bruce AW. Intra-cavitary Bacille Calmette Guerin in the treatment of superficial bladder tumors. J Urol 1976;116:180-3.

[30] Netto NR Jr, Lemos GC. Bacillus Calmette-Guerin immunotherapy of infiltrating bladder cancer. J Urol 1984; 132:675-7.

[31] Apolo AB. Effect of cabozantanib on immunosuppressive subsets in metastatic urothelial carcinoma. Proc Amer Soc Clin Oncol 2014;32:296s, abst. 4501.

[32] Powles T, Eder JP, Fine GD, et al. MPDL3280A (anti-PDL1) treatment leads to clinical activity in metastatic bladder cancer. Nature 2014;515:558-62.

[33] Barnes RW, Dick AL, Hadley HL, Johnston OL. Survival following transurethral resection of bladder carcinoma. Cancer Res 1977;37:2895-7.

[34] Herr HW. Conservative management of muscleinfiltrating bladder cancer: Prospective experience. J Urol 1987;138:1162.

[35] Holzbeierlein JM, Lopez-Corona E, Bochner BH, et al. Partial cystectomy: A contemporary review of the Memorial SloanKettering Cancer Center experience and recommendations for patient selection. J Urol 2004;172:878-81.

[36] Stein JP, Lieskovsky G, Cote R, et al. Radical cystectomy in the treatment of invasive bladder cancer: Long-term results in 1054 patients. J Clin Oncol 2001;19:666-75.

[37] Solsona E, Iborra I, Dumont R, Rubio J, Casanova JL, Almenar S. Risk groups in patients with bladder cancer treated with radical cystectomy: Statistical and clinical model improving homogeneity. J Urol 2005;174:1226-30.

[38] Lee CT, Madii R, Daignault S, et al. Cystectomy delay more than 3 months from initial bladder cancer diagnosis results in decreased disease specific and overall survival. J Urol 2006; 175:1262-7.

[39] Herr HW, Faulkner JR, Grossman HB, et al. Surgical factors influence bladder cancer outcomes. J Clin Oncol 2004;22:2781-9.

[40] Desai MM, Gill IS, de Castro Abreu AL, et al. Robotic intracorporeal orthotopic neobladder during radical cystectomy in 132 patients. J Urol 2014;192:1734-40.

[41] Kader AK, Richards KA, Krane LS, Pettus JA, Smith JJ, Hemal AK. Robot-assisted laparoscopic vs open radical cystectomy: Comparision of complications and perioperative oncological outcomes in 200 patients. BJU Int 2013;112:E290-4.

[42] Bochner BH, Sjoberg DD, Laudone VP, et al. A randomized trial of robot-assisted laparoscopic radical cystectomy. New Engl J Med 2014;371:389-90.

[43] Sternberg CN, Skoneczna I, Kerst JM, et al. Immediate versus deferred chemotherapy after radical cystectomy in patients with pT3-pT4 or N+M0 urothelial carcinoma of the bladder (EORTC 30994): An intergroup, open-label, randomised phase 3 trial. Lancet Oncol 2014, e-pub ahead of print.

[44] Mameghan H, Fisher RJ, Watt WH, et al. The management of invasive transitional cell carcinoma of the bladder: Results of definitive and preoperative radiation therapy in 390 patients treated at the Prince of Wales Hospital, Sydney, Australia. Cancer 1992;69:2771.

[45] Gospodarowicz MK, Hawkins NV, Rawlings GA, et al. Radical radiotherapy for uscle invasive transitional cell carcinoma of the bladder: Failure analysis. J Urol 1989;142:1448.

[46] Shipley WU, Prout GR Jr, Kaufman DS, Peronne TL. Invasive bladder carcinoma: The importance of initial transurethral surgery and other significant prognostic factors for improved survival with full-dose irradiation. Cancer 1987;60:514-20.

[47] Shipley WU, Kaufman DS, Zehr E, et al. Selective bladder preservation by combined modality protocol treatment: Longterm outcomes of 190 patients with invasive bladder cancer. Urology 2002;60:62-7.

[48] Krause FS, Walter B, Ott OJ, et al. 15-year survival rates after transurethral resection and radiochemotherapy or radiation in bladder cancer treatment. Anticancer Res 2011;31:985-90.

[49] Mak RH, Hunt D, Shipley WU, et al. Long-term outcomes in patients with muscle-invasive bladder cancer after selective bladder-preserving combined-modality therapy: A pooled analysis of Radiation Therapy Oncology Group protools 8802, 8903, 9506, 9706, 9906, and 0233. J Clin Oncol 2014;32:3801-9.

[50] Coppin CM, Gospodarowicz MK, James K, et al. Improved local control of invasive bladder cancer by concurrent cisplatin and preoperative or definitive radiation. The National Cancer Institute of Canada Clinical Trials Group. J Clin Oncol 1996;14:2901-7.

[51] James ND, Hussain SA, Hall E, et al. Radiotherapy with or without chemotherapy in muscle-invasive bladder cancer. N Engl J Med 2012;366:1477-88.

[52] Raghavan D, Pearson B, Coorey G, et al. Intravenous cisplatinum for invasive bladder cancer. Safety and feasibility of a new approach. Med J Aust 1984;140:276-8.

[53] Raghavan D, Pearson B, Duval P, et al. Initial intravenous cisplatinum therapy: Improved management for invasive high risk bladder cancer? J Urol 1985;133:399-402.

[54] Soloway MS, Ikard M, Scheinberg M, Evans J. Concurrent radiation and cisplatin in the treatment of advanced bladder cancer: A preliminary report. J Urol 1982;128:1031-3.

[55] Wallace DM, Raghavan D, Kelly KA, et al. Neo-adjuvant (pre-emptive) cisplatin therapy in invasive transitional cell carcinoma of the bladder. Br J Urol 1991;67:608-15.

[56] Sternberg CN, Yagoda A, Scher HI, et al. M-VAC (methotrexate, vinblastine, doxorubicin and cisplatin) for advanced transitional cell carcinoma of the urothelium. J Urol 1988;139:461-9.

[57] Harker WG, Meyers FJ, Freiha FS, et al. Cisplatin, methotrexate and vinblastine (CMV): An effective chemotherapy regimen for metastatic transitional cell carcinoma of the urinary tract. A Northern California Oncology Group study. J Clin Oncol 1985;3:1463-70.

[58] Loehrer PJ, Einhorn LH, Elson PJ, et al. A randomized comparison of cisplatin alone or in combination with methotrexate, vinblastine, and doxorubicin in patients with metastatic urothelial carcinoma: A cooperative group study. J Clin Oncol 1992;10:1066-72.

[59] Schultz PK, Herr HW, Zhang ZF, et al. Neoadjuvant chemotherapy for invasive bladder cancer: Prognostic factors for survival of patients treated with M-VAC with 5-year follow-up. J Clin Oncol 1994;12:1394-401.

[60] Fossa SD, Harland SJ, Kaye SB, Raghavan D, Russell JM, Parmar MK. Initial combination chemotherapy with cisplatin, methotrexate an vinblastine in locally advanced transitional cell carcinoma - response rate and pitfalls. MRC Subgroup in Advanced Bladder Cancer (on behalf of the MRC Urological Working Party). Br J Urol 1992;70:161-8.

[61] International Collaboration of Trialists on behalf of MRC Advanced Bladder Cancer Working Party, EORTC Genitourinary Group, Australian Bladder Cancer Study Group, et al. Neoadjuvant cisplatin, methotrexate, and vinblastine chemotherapy for muscle-invasive bladder cancer: A randomized controlled trial. The Lancet 1999;354:533-40. 
[62] Griffiths G, Hall R, Sylvester R, Raghavan D, Parmar M for International Collaboration of Trialists. International phase III trial assessing neoadjuvant cisplatin, methotrexate, and vinblastine chemotherapy for muscle-invasive bladder cancer: Long-term results of the BA06 30894 trial. J Clin Oncol 2011;29:2171-7.

[63] Shipley WU, Winter K, Kaufman D, et al. Phase III trial of neoadjuvant chemotherapy in patients with invasive bladder cancer treated with selective bladder preservation by combined radiation therapy and chemotherapy: Initial results of Radiation Therapy Oncology Group 89-03. J Clin Oncol 1998;16:3576-83.

[64] Grossman HB, Natale RB, Tangen CM, et al. Neoadjuvant chemotherapy plus cystectomy compared with cystectomy alone for locally advanced bladder cancer. N Engl J Med 2003;349:859-66.

[65] Malmstrom PU, Rintala E, Wahlqvist R, Hellstrom P, Hellsten $\mathrm{S}$, Hannisdal E. Five-year followup of a prospective trial of radical cystectomy and neoadjuvant chemotherapy: Nordic Cystectomy Trial 1. The Nordic Cooperative Bladder Cancer Study Group. J Urol 1996;155:1903-6.

[66] Advanced Bladder Cancer Meta-analysis Collaboration. Neoadjuvant chemotherapy in invasive bladder cancer: A systematic review and meta-analysis. Lancet 2003;361:1927-34.

[67] Freiha F, Reese J, Torti FM. A randomized trial of radical cystectomy plus cisplatin, vinblastine and methotrexate chemotherapy for muscle invasive bladder cancer. J Urol 1996; $155: 495-500$.

[68] Skinner DG, Daniels JR, Russell CA, et al. The role of adjuvant chemotherapy following cystectomy for invasive bladder cancer: A prospective comparative trial. J Urol 1991;145:45967.

[69] Lehman J, Franzaring L, Thuroff J, Wellek S, Stockle M. Complete long-term survival data from a trial of adjuvant chemotherapy vs control after radical cystectomy for locally advanced bladder cancer. BJU Int 2006;97:42-7.

[70] Stockle M, Wellek S, Meyenburg W, et al. Radical cystectomy with or without adjuvant polychemotherapy for non-organconfined transitional cell carcinoma of the urinary bladder: Prognostic impact of lymph node involvement. Urology 1996;48:868-75.

[71] Vale CL. Adjuvant chemotherapy in invasive bladder cancer: A systematic review and meta-analysis of individual patient data: Advanced Bladder Cancer (ABC) Meta-analysis Collaboration. Eur Urol 2005;48:189-201.

[72] Raghavan D, Bawtinhimer A, Mahoney J, Eckrich S, Riggs S. Adjuvant chemotherapy for bladder cancer - why does level 1 evidence not support it? Ann Oncol 2014;10:1930-4.

[73] Cognetti F, Ruggeri EM, Felici A, et al. Adjuvant chemotherapy with cisplatin and gemcitabine versus chemotherapy at relapse in patients with muscle-invasive bladder cancer submitted to radical cystectomy: An Italian, multicenter, randomized phase III trial. Ann Oncol 2011;23:695-700.

[74] David KA, Milowsky MI, Ritchey J, Carroll PR, Nanus DM. Low incidence of perioperative chemotherapy for stage III bladder cancer 1998 to 2003: A report from the National Cancer Data Base. J Urol 2007;178:451.

[75] Porter MP, Kerrigan MC, Donato BM, Ransey SD. Patterns of use of systemic chemotherapy for Medicare beneficiaries with urothelial bladder cancer. Urol Oncol 2011;29:252-8.

[76] Miles BJW, Fairey AS, Eliasziw M, et al. Referral and treatment rates of neoadjvuant chemotherapy in muscle-invasive bladder cancer before and after publication of a clinical practice guideline. Can Urol Assoc J 2010;4:263-7.

[77] Raj GV, Karavadia S, Schlomer B, et al. Contemporary use of perioperative cisplatin-based chemotherapy in patients with muscle-invasive bladder cancer. Cancer 2011;117:276-82.

[78] von der Maase H, Sengelov L, Roberts JT, et al. Long-term survival results of a randomized trial comparing gemcitabine plus cisplatin, with methotrexate, vinblastine, doxorubicin, plus cisplatin in patients with bladder cancer. J Clin Oncol 2005;23:4602-8.

[79] Bellmunt J, von der Maase H, Mead GM, et al. Randomized phase III study comparing paclitaxel/cisplatin/gemcitabine and gemcitabine/cisplatin in patients with locally advanced or metastatic urothelial cancer without prior systemic therapy: EORTC Intergroup Study 30987. J Clin Oncol 2012;30: 1107-13.

[80] Paz-Ares LG, Solsona E, Esteban E, et al. Randomized phase III trial comparing adjuvant paclitaxel/gemcitabine/cisplatin (PGC) to observation in patients with resected invasive bladder cancer: Results of the Spanish Oncology Genitourinary Group (SOGUG) 99/01 study Proc. Amer Soc Clin Oncol 2010, abstract LBA4518.

[81] Pruthi RS, Nielsen M, Heathcore S, et al. A phase II trial of neoadjuvant erlotinib in patients with muscle-invasive bladder cancer undergoing radical cystectomy: Clinical and pathological results. BJU Int 2010;106:349-54.

[82] Dancik G, Aisner D, Theodorescu D. A 20 gene model for predicting nodal involvement in bladder cancer patients with muscle invasive tumors. PLoS Curr 2011;3, RRN 1248.

[83] Dinney CP, Hansel D, McConkey D, et al. Novel neoadjuvant therapy paradigms for bladder cancer: Results from the National Cancer Center Institute Forum. Urol Oncol 2014;32:1108-15.

[84] Mitra AP, Lam LL, Ghadessi M, et al. Discovery and validation of novel expression signature for postcystectomy recurrence in high-risk bladder cancer. JNCI 2014;106(11):dju290, doi: 10.1093/jnci/dju290. 